\title{
The Phillips Curve in the United States and Canada: A GARCH- DCC Analysis
}

\author{
Lu Yang ${ }^{\mathrm{a}}$ and Shigeyuki Hamori ${ }^{\mathrm{b},{ }^{*}}$ \\ ${ }^{a}$ Graduate School of Economics, Kobe University, 2-1 Rokkodai, Nada-Ku, Kobe 657-8501, Japan \\ ${ }^{b}$ Faculty of Economics, Kobe University, 2-1 Rokkodai, Nada-Ku, Kobe 657-8501, Japan
}

\begin{abstract}
By applying the GARCH-DCC model, we reexamine the Phillips curve based on a time-varying correlation analysis for Canada and the United States from January 1985 to December 2012. The empirical results show that the sign of the correlation between the inflation rate and the unemployment rate is negative during recession periods but positive during boom periods.
\end{abstract}

Keywords: GARCH-DCC model, Phillips curve, financial crisis.

\section{INTRODUCTION}

The Phillips curve, which characterizes the negative relationship between the inflation rate and the unemployment rate, is considered to be one of the most important stylized facts in macroeconomics. Empirical evidence of UK wage behavior was originally provided by Phillips (1958) and interpreted theoretically by Lipsey (1960), offering policymakers the choice between inflation and unemployment. Since then, numerous empirical studies have been provided and the estimated Phillips curve has been found to be rather unstable over time and its use not justified for a long time span (see Friedman, 1968; Mankiw, 2000; Rubio et al., 2007).

In particular, numerous studies have examined the inflation-unemployment relation for the US economy. For example, Karanassou and Sala (2010) state that the US Phillips curve is not vertical even in the longrun. Their results imply that the nominal and real sides of the economy are symbiotic. Moreover, Sachsida et al. (2011) find important long-run co-movement between inflation and unemployment in the US economy. Further, Cevik and Dibooglu (2013) find that although shocks to US unemployment dissipate in expansions, shocks to the unemployment rate seem to be persistent in recessions.

In contrast to the studies above, we investigate the dynamic correlation between inflation and unemployment by considering the autoregressive conditional heteroskedasticity $(\mathrm{ARCH})$ effect. A notable addition to the body of knowledge on this topic was the recent

*Address correspondence to this author at the Faculty of Economics, Kobe University, 2-1 Rokkodai, Nada-Ku, Kobe 657-8501, Japan;

Tel: +81 0788036832; E-mail: hamori@econ.kobe-u.ac.jp study of Phillips curves by Russell and Chowdhury (2013), which retrieved the standard empirical results of Phillips curves based on a GARCH (generalized autoregressive conditional heteroskedasticity) model with structural breaks. Rather than focus on the stable relationship between the inflation rate and the unemployment rate in the long-term, however, the present paper allows for time-varying correlations in this relation by considering time series properties such as serial correlations, the $\mathrm{ARCH}$ process, and fat tails. The presence of these properties can prevent traditional econometric methods from accurately describing the Phillips curve. Therefore, we employ the GARCH-DCC (dynamic conditional correlation) model (Rahman and Serletis, 2012; Jones and Olson, 2013) to solve the discussed problem and select Canada and the United States to be our case studies for comparison and contrasting purposes. In contrast to the study of Russell and Chowdhury (2013), the present paper focuses on an empirical methodology by using DCC to examine the Phillips curves in these countries.

\section{METHODOLOGY}

We follow the study of Hamilton (2008) by modeling the series presented herein as a GARCH process. Further, we apply Engle's (2002) DCC techniques to describe the time-varying correlations between the inflation rate and the unemployment rate.

Let $y_{t}=\left[y_{1}, y_{2 t}\right]^{\prime}$ be a $2 \times 1$ vector that contains the data series on the inflation rate and the unemployment rate. The VAR (vector autoregression) can be expressed as follows:

$$
A(L) y_{t}=\varepsilon_{t}
$$


where $A(L)$ is a matrix in the lag operator $L$ and $\varepsilon_{t}=\left[\varepsilon_{1 t}, \varepsilon_{2 t}\right]^{\prime}$ is a vector of innovations. Equation 1 , the $\operatorname{VAR}(k)$ model, indicates that the current movement of variables $y_{t}$ can be explained by their own past movements $\left(y_{t-1}, y_{t-2}, \cdots\right)$.

The innovation process is ruled by the following $\operatorname{GARCH}(p, q)$ process:

$h_{i, t}=\omega_{i}+\sum_{i=1}^{p} \alpha_{i} \varepsilon_{i, t-1}^{2}+\sum_{i=1}^{q} \beta_{i} h_{i, t-1}(i=1,2)$

where $E_{t-1}$ is the conditional information operator based on the information at time $t-1$.

We apply DCC to illustrate the dynamic relationship between the inflation rate and the unemployment rate. Specifically, based on the conditional volatilities from Equation 2, we calculate the conditional correlations from the conditional covariance matrix as

$H_{t}=E\left[\varepsilon_{t} \varepsilon_{t}^{\prime}\right]=D_{t} R_{t} D_{t}$

where the diagonal matrix $D_{t}$ represents the conditional volatilities from Equation 2.

Engle (2002) considers a dynamic matrix process

$Q_{t}=\left(\bar{Q}-A^{\prime} \bar{Q} A-B^{\prime} \bar{Q} B\right)+A^{\prime} z_{t-1} z_{t-1}^{\prime} A+B^{\prime} Q_{t-1} B$ where $\bar{Q}$ represents the unconditional correlation matrices of $z_{t}$.Then, the conditional correlation matrix $R_{t}$ is derived as

$R_{t}=Q_{t}^{*-1} Q_{t} Q_{t}^{*-1}$

where the diagonal matrix $Q_{t}^{*}=\sqrt{q_{i i, t}}$ contains the square roots of the diagonal elements of $Q_{t}$.

In particular, the bivariate DCC can be specified as

$q_{i j, t}=\left(\bar{q}-a^{2} \bar{q}-b^{2} \bar{q}\right)+a^{2} z_{i j, t-1}+b^{2} q_{i j, t-1}$

where $z_{i, t-1}$ is the time-varying vector of standardized residuals $\frac{\varepsilon_{i, t-1}}{h_{i, t-1}}$ and the restriction condition is $a^{2}+b^{2}<1$.

\section{DATA}

To analyze the Phillips curve of price and unemployment, we employ the monthly consumer price index (CPI) and unemployment rate in Canada and the United States from January 1985 to December 2012. The inflation rate is computed as 1200 times the log monthly change in the CPI. All seasonally adjusted data series are derived from DataStream. The descriptive statistics are reported in Table 1.

Table 1: Descriptive Statistics for the Inflation Rate and the Unemployment Rate

\begin{tabular}{|c|c|c|c|c|}
\hline \multirow{2}{*}{} & \multicolumn{2}{|c|}{ The United States } & \multicolumn{2}{c|}{ Canada } \\
\cline { 2 - 5 } & Inflation & Unemployment & Inflation & 2.262 \\
\hline \hline Mean & 2.801 & 6.099 & 2.184 & 7.900 \\
\hline Median & 2.793 & 5.700 & 9.477 & 12.100 \\
\hline Maximum & 16.409 & 10.000 & -3.898 & 5.900 \\
\hline Minimum & -21.437 & 3.800 & 2.059 & 1.514 \\
\hline Std. Dev. & 3.138 & 1.510 & 0.258 & 0.520 \\
\hline Skewness & -1.563 & 0.849 & 3.867 & 2.330 \\
\hline Kurtosis & 15.663 & 3.010 & 14.240 & 21.426 \\
\hline Jarque-Bera & 2381.690 & 40.396 & $-3.274^{* *}$ & -1.516 \\
\hline Unit root test (ADF) & $-11.681^{* * *}$ & -2.297 & & $-6.489^{* * *}$ \\
\hline Zivot-Andrews Test & & $-4.665^{* *}$ & $3479.784^{* * *}$ & $3490.459^{* * *}$ \\
\hline Q(12) & $77.173^{* * *}$ & 336 & 336 & 336 \\
\hline Obs & 336 & $3 \%$ & \\
\hline
\end{tabular}

Notes: ** and ${ }^{* *}$ represent significance at the $5 \%$ and $1 \%$ levels, respectively. $Q(12)$ is the Ljung-Box $Q$ statistics for the null hypothesis that there is no autocorrelation up to order 12 for standardized residuals.

Source: DataStream. 


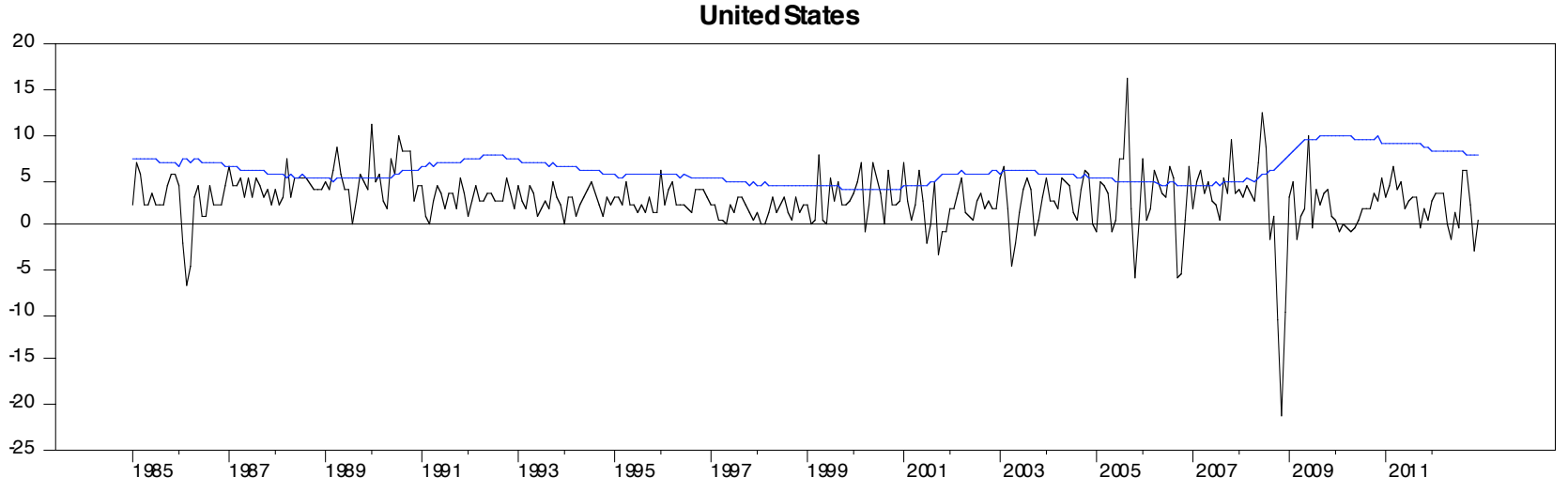

Figure 1: Time series plots of the inflation rate (black) and the unemployment rate (blue).

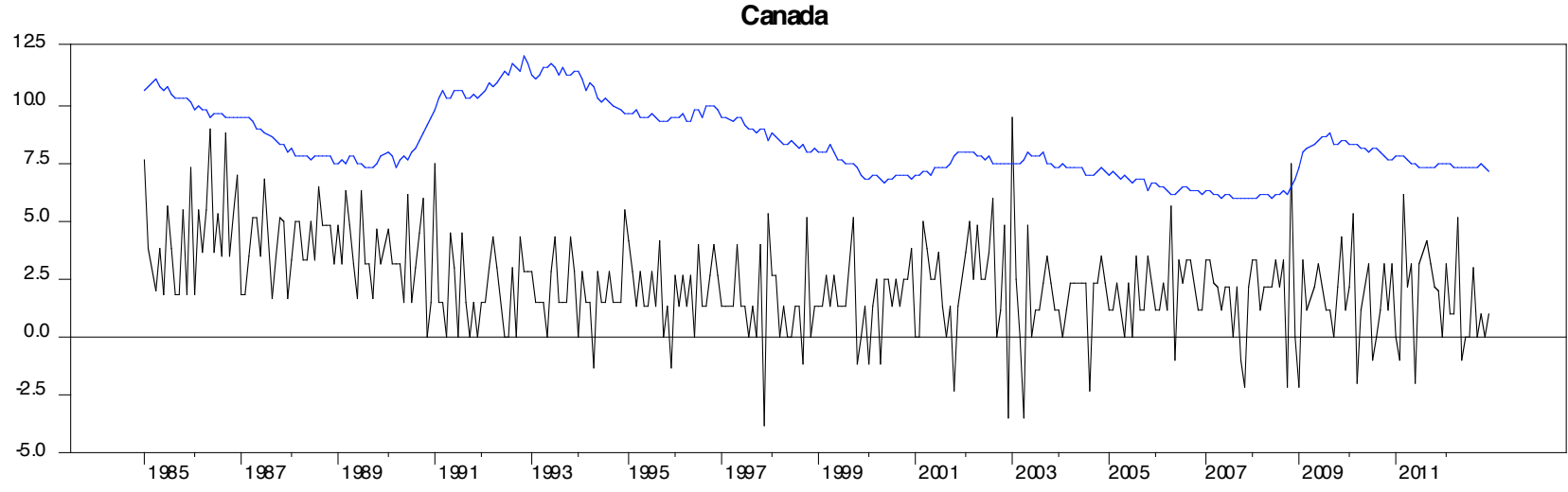

Figure 2: Time series plots of the inflation rate (black) and the unemployment rate (blue).

Based on augmented Dickey-Fuller (ADF) tests, the inflation rate is found to be stationary, while the unemployment rate contains a unit root. However, since Perron's (1989) analyses show that structural breaks can lead to erroneously accepting unit roots, we also implement the Zivot and Andrews (1992) unit root test for the unemployment rate. This test indicates that the unemployment rate is stationary in levels with a structural break occurring in November 2008 for Canada and in May 2008 for the United States. To account for these structural breaks, we incorporate a dummy variable $(D=1)$ into Equation 1 for all $t \geq$ November 2008 in Canada and for all $t \geq$ May 2008 in the United States. The results of the Jarque-Bera test indicate that the null hypothesis of normality is rejected for all cases, which indirectly supports the existence of $\mathrm{ARCH}$ effects. The results of the Ljung-Box $Q$ statistics demonstrate that the null hypothesis of no autocorrelation up to order 12 is rejected at the $1 \%$ level for all cases. These data series are plotted in Figures 1 and 2.

\section{EMPIRICAL RESULTS}

The results are shown in Table 2. Most of the estimates in the variance equation are statistically significant at the $10 \%$ level, and they satisfy the restrictions of $\omega>0, \alpha>0, \beta>0, \alpha+\beta<1$, which confirms that GARCH-type models are appropriate. The coefficients in the DCC model are also estimated to be statistically significant at the $10 \%$ level, and these also satisfy the restrictions of $a^{2}+b^{2}<1$. The Ljung-Box $Q$ statistics also suggest that the empirical results of the models have been adequately estimated.

Figures $\mathbf{3}$ and $\mathbf{4}$ display the time-varying correlations from the estimated models. The correlation between the inflation rate and the unemployment rate tends to range from -0.25 to 0.15 for the United States and from -0.24 to 0.13 for Canada. During the economic recession and contraction periods (i.e., the 2000s for Canada and 2001-2004 for the United States), a negative correlation between the inflation rate and the unemployment rate consistently exists. However, a continuous positive relationship between 
Table 2: Bivariate GARCH-DCC Model

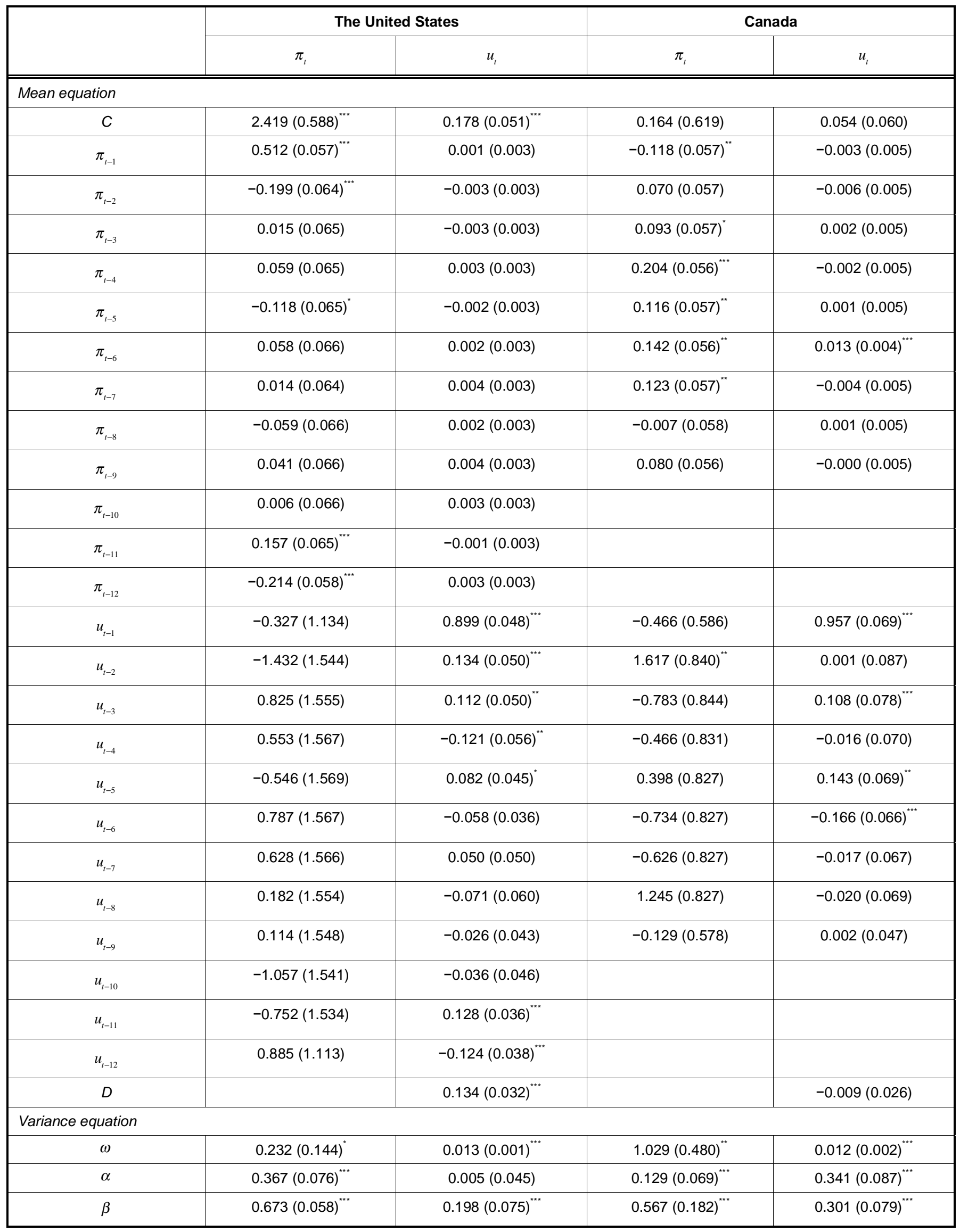


(Table 2). Continued.

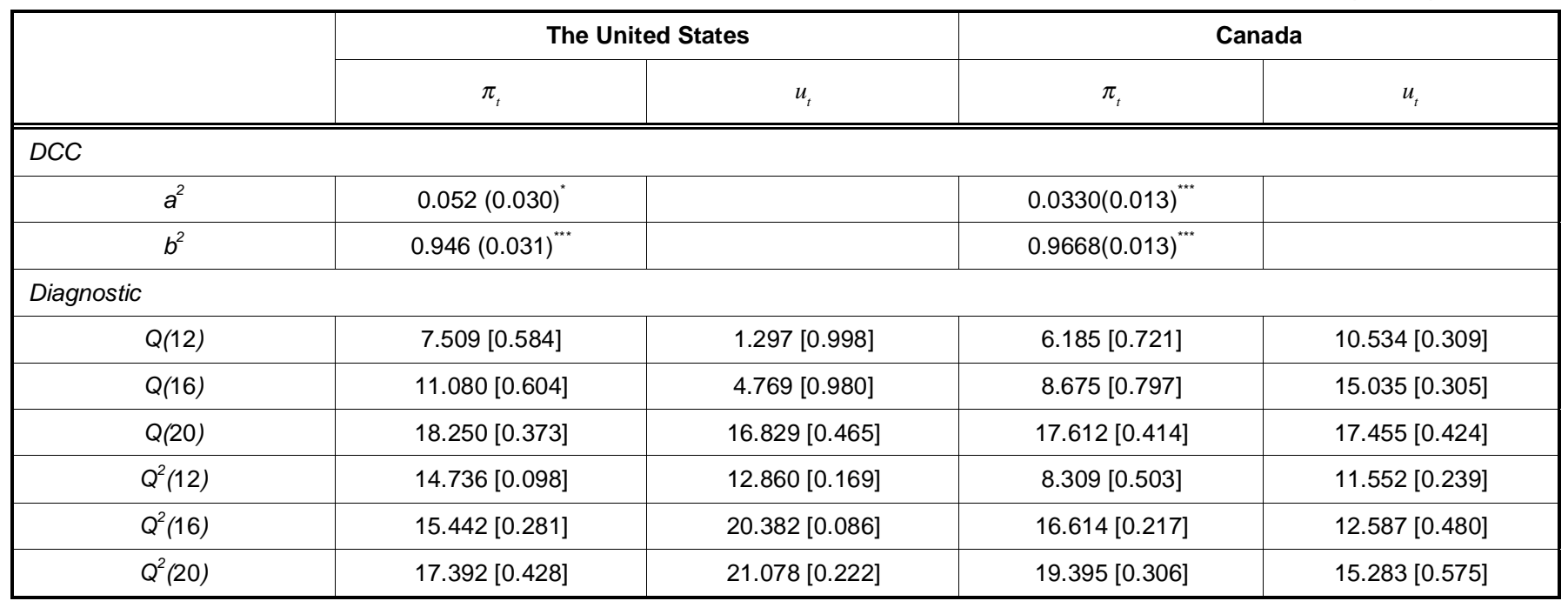

Notes: $\pi_{t}$ and $u_{t}$ denote the inflation rate and the unemployment rate at time $t$, respectively. The numbers in parentheses are standard errors. The numbers in square brackets are $p$-values. $Q(12), Q(16)$, and $Q(20)\left(Q^{2}(12), Q^{2}(16)\right.$, and $\left.Q^{2}(20)\right)$ are the Ljung-Box $Q$ statistics for the null hypothesis that there is no autocorrelation up to orders 12,16 , and 20 for standardized residuals (standardized squared residuals), respectively. ${ }^{*},{ }^{* *}$, and ${ }^{* * *}$ represent significance at the $10 \%$, $5 \%$, and $1 \%$ levels, respectively.

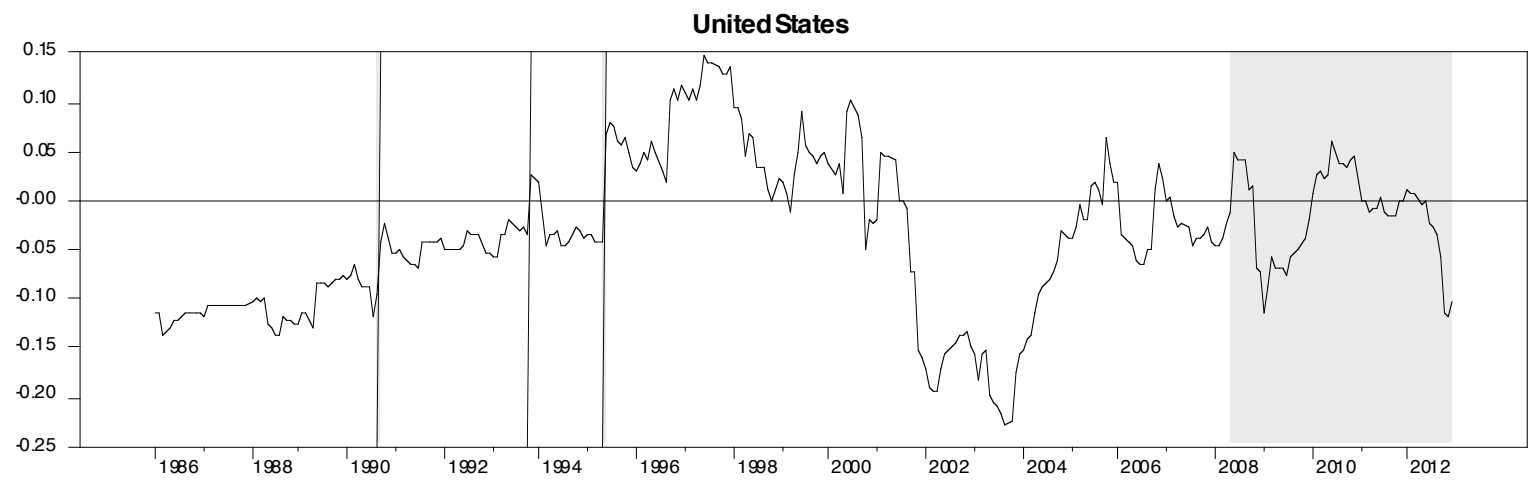

Figure 3: Conditional correlation between the inflation rate and the unemployment rate.

Notes: The shaded portion of the figure represents the dates after the structural break in the unemployment rate. The dashed lines from left to right denote the 1990 oil price spike, Black Wednesday in 1992, and the economic crisis in Mexico in 1994, respectively.

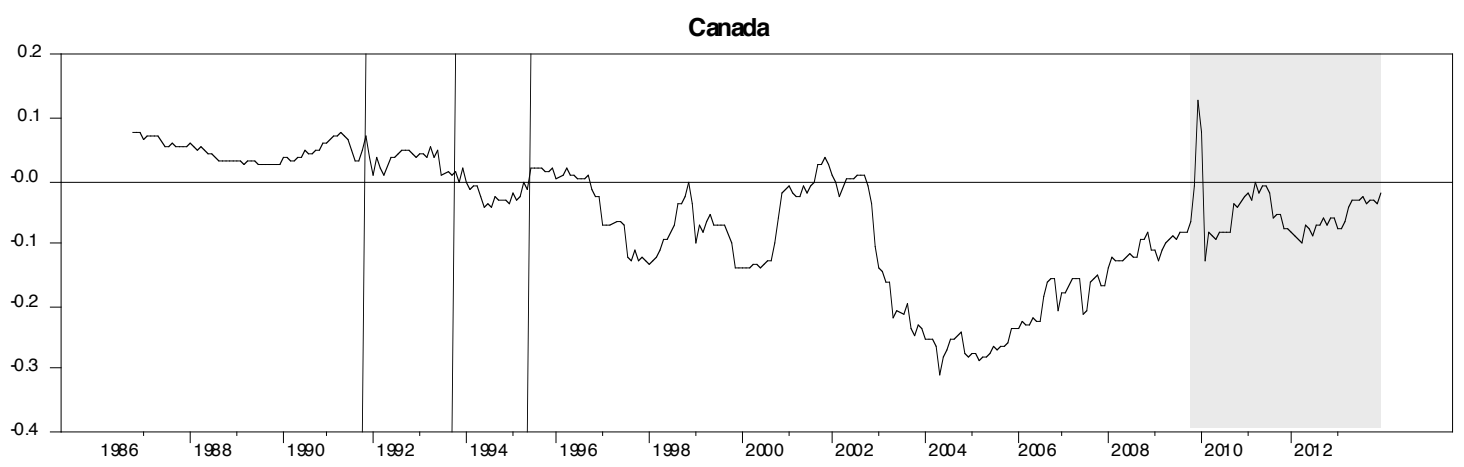

Figure 4: Conditional correlation between the inflation rate and the unemployment rate.

Notes: The shaded portion of the figure represents the dates after the structural break in the unemployment rate. The dashed lines from left to right denote the 1990 oil price spike, Black Wednesday in 1992, and the economic crisis in Mexico in 1994, respectively.

the inflation rate and the unemployment rate is observed in the United States from 1995 to 1999 due to the IT bubble, and the same phenomenon is detected in Canada from 1985 to 1989 due to the Toronto bubble. 
Consistent with the findings of Sachsida et al. (2011) and Cevik and Dibooglu (2013), the Phillips curves estimated in this study proved to be rather unstable in the long run for the economies of both Canada and the United States. In contrast to the findings of previous studies, however, we show that a negative inflation-unemployment relationship does not exist during economic booms. Moreover, monetary policy, perhaps by stimulating inflation, seems to be more effective at reducing unemployment during recession periods.

\section{CONCLUSION}

By applying the GARCH-DCC model, we reexamined the Phillips curves of price and unemployment for the United States and Canada from January 1985 to December 2012. Compared with previous studies, the empirical results found a negative correlation during periods of contraction and recession but a positive correlation during periods of relatively rapid economic growth. For example, the IT bubble in the United States from 1995 to 1999 and Toronto bubble in Canada from 1985 to 1989 exhibited positive correlations between the inflation rate and the unemployment rate.

Our results have at least two implications for policymakers. First, monetary policy may have more important and long-lasting effects on unemployment during a recession period compared with during a tranquil period. Second, since keeping the unemployment rate at a reasonable level is the priority of monetary authorities, the tradeoff between inflation and unemployment must be evaluated before implementing any policy, especially when the economy is booming.

\section{ACKNOWLEDGEMENTS}

We are grateful to an anonymous referee for helpful comments and suggestions. The research of the second author is in part supported by a Grant-in-Aid from the Japan Society for the Promotion of Science.

\section{REFERENCES}

Cevik, E.I., Dibooglu, S. (2013) Persistence and non-linearity in US unemployment: A regime-switching approach. Economic Systems, 37, 61-68. http://dx.doi.org/10.1016/j.ecosys.2012.06.002

Engle, R. (2002) Dynamic conditional correlation: a simple class of multivariate generalized autoregressive conditional heteroskedasticity models. Journal of Business \& Economic Statistics, 20, 339-350. http://dx.doi.org/10.1198/073500102288618487

Friedman, M. (1968) The role of monetary policy. American Economic Review, 58, 1-17.

Hamilton, J. (2008) Macroeconomics and ARCH. Mimeo, University of California, San Diego. http://dx.doi.org/10.3386/w14151

Jones, P.M., Olson, E. (2013) The time-varying correlation between uncertainty, output, and inflation: Evidence from a DCCGARCH model. Economics Letters, 118, 33-37. http://dx.doi.org/10.1016/j.econlet.2012.09.012

Karanassou, M., Sala, H. (2010) The US inflation-unemployment trade-off revisited: New evidence for policy-making. Journal of Policy Modeling, 32, 758-777. http://dx.doi.org/10.1016/j.jpolmod.2010.08.004

Lipsey, R.G. (1960) The relation between unemployment and the rate of change of money wage rates in the United Kingdom, 1862-1957: A further analysis, Economica, 27, 1-31. http://dx.doi.org/10.2307/2551424

Mankiw, N.G. (2000) The inexorable and mysterious tradeoff between inflation and unemployment. Economic Journal, $111,45-61$. http://dx.doi.org/10.1111/1468-0297.00619

Phillips, A.W. (1958) The relation between unemployment and the rate of change of money wage rates in the United Kingdom, 1862-1957. Economica, 25, 283-299.

Perron, P. (1989) The great crash, the oil price shock, and the unit root hypothesis. Econometrica, 57, 1361-1401. http://dx.doi.org/10.2307/1913712

Rahman, S., Serletis, A. (2012) Oil price uncertainty and the Canadian economy: Evidence from a VARMA, GARCH-inMean, asymmetric BEKK model. Energy Economics, 34, 603-610. http://dx.doi.org/10.1016/i.eneco.2011.08.014

Rubio, O.B., Roldán, C.D., Esteve, V. (2007) Change of regime and Phillips curve stability: the case of Spain, 1964-2002. Journal of Policy Modeling, 29, 453-462. http://dx.doi.org/10.1016/j.jpolmod.2006.06.017

Russell, E., Chowdhury, R.A. (2013) Estimating Unites States Phillips curves with expectation consistent with the statistical process of inflation. Journal of Macroeconomics, 35, 24-38. http://dx.doi.org/10.1016/j.jmacro.2012.11.004

Sachsida, A., Divino, J.A., Cajueiro, D.O. (2011) Inflation, unemployment, and the time consistency of the US monetary policy. Structural Change and Economic Dynamics, 22, 173179.

http://dx.doi.org/10.1016/j.strueco.2010.12.002

Zivot, E., Andrews, D.W.K. (1992) Further evidence on the great crash, the oil-price shock and the unit root hypothesis. Journal of Business \& Economic Statistics, 10, 251-270.

\section{DOI: http://dx.doi.org/10.6000/1929-7092.2014.03.01}

(c) 2014 Yang and Hamori; Licensee Lifescience Global.

This is an open access article licensed under the terms of the Creative Commons Attribution Non-Commercial License (http://creativecommons.org/licenses/by-nc/3.0/) which permits unrestricted, non-commercial use, distribution and reproduction in any medium, provided the work is properly cited. 